\title{
New Extractive Method Development of Sitagliptin Phosphate in API and Its Unit Dosage Forms by Spectrophotometry
}

\author{
N.Monila ${ }^{1}$, Ravi Pratap Pulla ${ }^{1}$, Harshini Shabad ${ }^{1}$, V.Swathi ${ }^{1}$, J.Rajasekhar ${ }^{1}$, \\ A.Ramesh ${ }^{1}$, B.Koti Reddy ${ }^{2} \&$ B.Umashankar ${ }^{2}$ \\ ${ }^{I}$ Dept. of Pharmaceutical Analysis, SSJ College of Pharmacy, V.N.Pally, Gandipet, Hyderabad - 500 075, \\ Andhra Pradesh, India. \\ ${ }^{2}$ Dept. of Pharmaceutical Analysis, Dr.Samuel George Institute of Pharmaceutical Sciences, Markapur, \\ Prakasham (District) - 523 316, Andhra Pradesh, India.
}

\begin{abstract}
Two simple, accurate, sensitive and reproducible visible spectrophotometric methods $(A \& B)$ have been developed for the determination of Sitagliptin Phosphate (SGP) in bulk and also in pharmaceutical formulations. The proposed methods are based on complexation of the drug with Bromo Thymol Blue (BTBMethod A) \& Bromo Cresol Green (BCG-Method B), extracted with chloroform, showing absorbance maxima at $412 \mathrm{~nm}$ and $419 \mathrm{~nm}$ respectively. Beer's law is obeyed over a concentration range of $25-125 \mu \mathrm{g} / \mathrm{ml}$ and 10-50 $\mu \mathrm{g} / \mathrm{ml}$ respectively. Results of analysis for the two methods established, were validated statistically and also by recovery studies.

All the variables were studied to optimize the reaction conditions. No interference was observed in the presence of common pharmaceutical excipients. The validity of the methods was tested by analyzing the drug in its pharmaceutical preparations. Good recoveries were obtained. The developed methods employed were successful for the determination of Sitagliptin Phosphate in various pharmaceutical preparations.
\end{abstract}

Keywords: Visible spectrophotometric method, SGP, BTB, BCG \& Molar Absorptivity

\section{Introduction}

Sitagliptin Phosphate is chemically 7-[(3R)-3-Amino-1-oxo-4-(2,4,5 Trifluorophenyl) butyl]-5,6,7,8Tetrahydo-3-(Trifluoromethyl)-1,2,4-Triazolo [4,3-a] pyrazine phosphate (1:1) monohydrate (Figure 1). Sitagliptin Phosphate is the first and only prescription medication in a new class of oral antihyperglycemic agents, which enhance the body's own ability to lower blood glucose when it is elevated. The therapeutic combination in Type II is the use of the orally active Dipeptidyl Peptidase-4 (DPP - IV) inhibitors (1-3) like Sitagliptin Phosphate. It is an oral anti-diabetic drug (4-8) that helps to control blood sugar levels by regulating the levels of insulin in the body.

A survey of literature reveals that, the analytical methods reported for Sitagliptin Phosphate were based upon Spectrophotometry $(9-12)$, HPLC $(13,14)$ and other related analytical techniques like Tandem Mass Spectroscopy $(15,16)$. As highlighted earlier, the use of the above drug has become, very wide spread. It is however, surprising to note that, not even a single method is available till now, for the extractive method development of the drug. The present article seeks to bridge this gap by developing a simple, sensitive, accurate, rapid and economical visible spectrophotometric method in the pure form and its tablet formulation as per ICH guidelines.<smiles>NC(CC(=O)N1CCn2c(nnc2C(F)(F)F)C1)Cc1cc(F)c(F)cc1F</smiles>

Figure 1: 7-[(3R)-3-Amino-1-oxo-4-(2, 4, 5 Trifluorophenyl) butyl]-5, 6, 7, 8-Tetrahydo-3(Trifluoromethyl)-1, 2, 4-Triazolo [4, 3-a] pyrazine phosphate (1:1) monohydrate

\section{Instrument}

\section{Experimental}

ELICO Double Beam UV-visible Spectrophotometer SL-244 with $1 \mathrm{~cm}$ matched pair quartz cells was used for all the spectral measurements. 


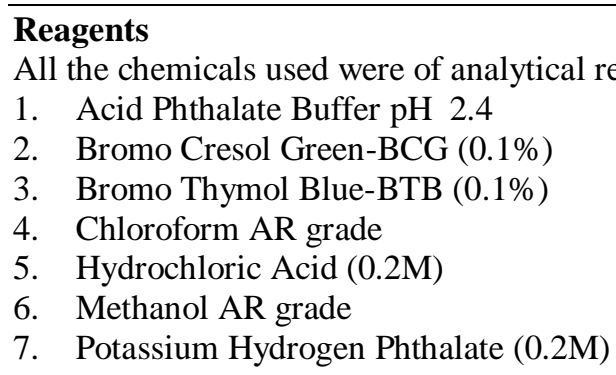

\section{Preparation of Stock Solution}

III. Procedure

A standard stock solution containing $1 \mathrm{mg} / \mathrm{ml}$ was prepared by dissolving $100 \mathrm{mg}$ of Sitagliptin Phosphate in $10 \mathrm{ml}$ of methanol, shake well till it dissolves and make up to $100 \mathrm{ml}$ with the same for both the methods A \& B.

\section{Preparation of Working Standard Solution}

From the above stock solution, working standard solution was prepared from $25-125 \mu \mathrm{g} / \mathrm{ml}$ for method A (100 $\mu \mathrm{g} / \mathrm{ml})$ and $10-50 \mu \mathrm{g} / \mathrm{ml}(50 \mu \mathrm{g} / \mathrm{ml})$ for method B respectively.

\section{METHOD A}

\section{Assay Procedure}

Aliquots of standard drug solution of Sitagliptin Phosphate containing 0.5-2.5 ml $(25-125 \mu \mathrm{g} / \mathrm{ml})$ were taken and transferred into series of graduated test tubes. To each test tube $2 \mathrm{ml}$ of Bromo Thymol Blue, $2 \mathrm{ml}$ of Phthalate buffer $\mathrm{pH} 2.4$ and $5 \mathrm{ml}$ of Chloroform were added. The solutions were shaken for 2 to 3 minutes and kept aside for the formation of colored complex. The absorbance of the yellow colored chromogen was measured at $412 \mathrm{~nm}$ against reagent blank and a calibration curve was constructed as depicted in Figure $2 \& 3$. The absorbance of the sample solution was measured, and the amount of the drug was determined by referring to the calibration curve or computed from the regression equation.

METHOD B

Aliquots of standard drug solution of Sitagliptin Phosphate containing 0.5-1.0 ml (10-50 $\mu \mathrm{g} / \mathrm{ml})$ were taken and transferred into series of graduated test tubes. To each test tube $1 \mathrm{ml}$ of Bromo Cresol Green, $2 \mathrm{ml}$ of Phthalate buffer $\mathrm{pH} 2.4$ and $5 \mathrm{ml}$ of Chloroform were added. The solutions were shaken for 2 to 3 minutes and kept aside for the formation of colored complex. The absorbance of the yellow colored chromogen was measured at $419 \mathrm{~nm}$ against reagent blank and a calibration curve was constructed as shown in Figure $4 \& 5$. The absorbance of the sample solution was measured, and the amount of the drug was determined by referring to the calibration curve or computed from the regression equation.

\section{Preparation Of The Sample Solution}

Ten tablets of Sitagliptin Phosphate were accurately weighed and powdered. Tablet powder equivalent to $100 \mathrm{mg}$ of Sitagliptin Phosphate was dissolved in $50 \mathrm{ml}$ of methanol, sonicated for $15 \mathrm{mins}$ and filtered. The filtrate is combined and the final volume was made to $100 \mathrm{ml}$ with methanol for the above method. The solution was suitably diluted and analyzed as given under the assay procedure for bulk sample. The analysis procedure was repeated three times with Tablet formulations and the results of analysis for both the methods A \& B were shown in Table: 1.

\section{Recovery Studies}

To ensure the accuracy and reproducibility of the results obtained, known amounts of the pure drug was added to the previously analyzed formulates samples and these samples were reanalyzed by the proposed method and also preformed recovery studies. The percentage recoveries, thus obtained for methods A \& B were given in Table: 1.

\section{Results And Discussion}

The optimum conditions were established by varying one parameter at a time and keeping the others fixed and observing the effect on absorbance of chromogen. In the present work, methods A \& B have been developed for the estimation of Sitagliptin Phosphate from tablet formulation. The developed methods A \& B are based on formation of chloroform extractable colored complexes with Bromo Thymol Blue \& Bromo Cresol Green respectively. The conditions required for the formation of colored complexes to form colored species were optimized. 
Statistical analysis was carried out and the results were found to be satisfactory. Relative standard deviation values were low indicating the reproducibility of the proposed methods. Recovery studies were close to $100 \%$ that indicates the accuracy and precision of the proposed methods. The optical characteristics such as absorption maxima, Beer's law limits, molar absorptivity, Sandell's sensitivity and other parameters are presented in Table: 2

\section{Conclusion}

The new procedure for the spectroscopic determination of Sitagliptin Phosphate described in this work is simple, rapid and cost-effective with high accuracy and precision when compared with previously reported procedures. It could find application as a convenient technique for the in-process control analysis of Sitagliptin Phosphate in bulk and its pharmaceutical formulations.

\section{Acknowledgements}

The authors are grateful to M/s MSD Pharmaceuticals Pvt.Ltd, Mumbai for the supply of Sitagliptin Phosphate as a gift sample and also to the Management and Principal Dr.K.Vanitha Prakash, SSJ College of Pharmacy, Gandipet, Hyderabad, Andhra Pradesh for providing us necessary facilities.

Figure 2: Absorption Spectrum of Sitagliptin Phosphate with Bromo Thymol Blue (Method A)

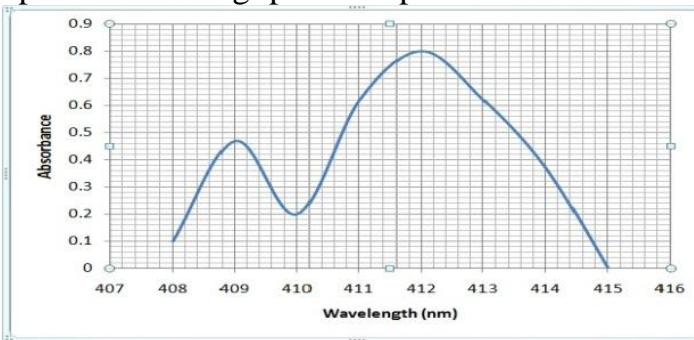

Figure 3: Linearity calibration curve of Sitagliptin Phosphate with Bromo Thymol Blue (Method A)

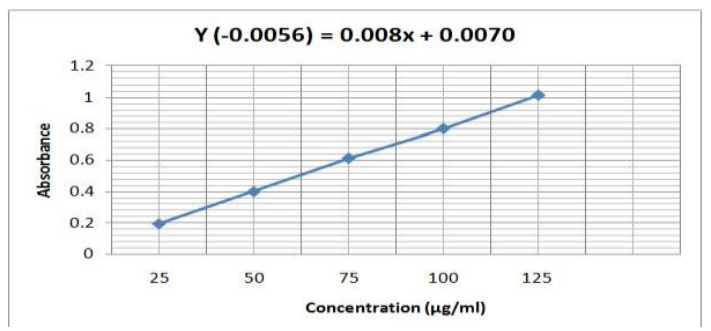

Figure 4: Absorption Spectrum of Sitagliptin Phosphate with Bromo Cresol Green (Method B)

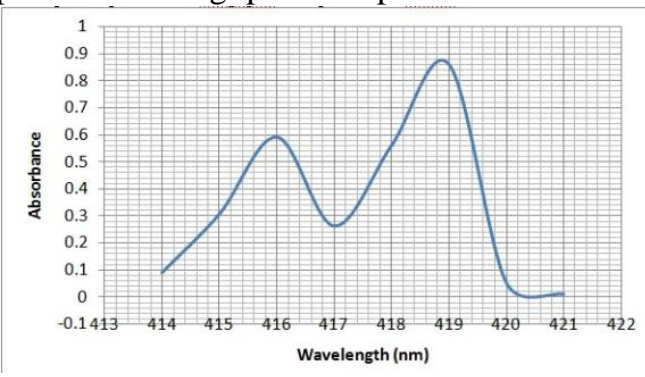

Figure 5: Linearity calibration curve of Sitagliptin Phosphate with Bromo Cresol Green (Method B)

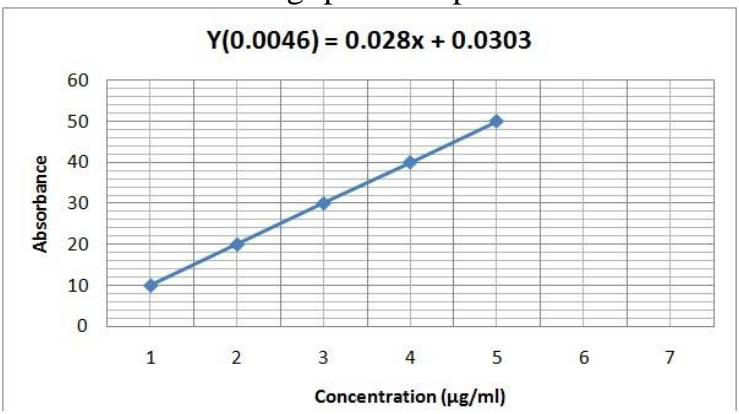

www.iosrjournals.org 
Table 1: Assay of Sitagliptin Phosphate in Tablet Formulation by Methods A \& B

\begin{tabular}{|c|c|c|c|c|c|}
\hline \multirow[t]{2}{*}{$\begin{array}{c}\text { Tablet } \\
\text { Formulation }\end{array}$} & \multirow[t]{2}{*}{$\begin{array}{c}\text { Amount } \\
\text { claim } \\
\text { (mg/tablet) }\end{array}$} & \multicolumn{2}{|c|}{$\begin{array}{c}\text { *amount obtained (mg) } \\
\text { by the proposed } \\
\text { methods }\end{array}$} & \multicolumn{2}{|c|}{$\begin{array}{c}* * \% \text { Recovery by } \\
\text { the proposed } \\
\text { methods }\end{array}$} \\
\hline & & $\begin{array}{c}\text { Method } \\
\text { A }\end{array}$ & $\begin{array}{c}\text { Method } \\
\text { B }\end{array}$ & $\begin{array}{c}\text { Method } \\
\text { A }\end{array}$ & $\begin{array}{c}\text { Method } \\
\text { B }\end{array}$ \\
\hline 1 & 100 & 99.31 & 98.77 & 102.28 & 98.73 \\
\hline 2 & 100 & 98.27 & 99.43 & 101.19 & 99.45 \\
\hline 3 & 100 & 98.74 & 101.24 & 100.83 & $\begin{array}{l}101.89 \\
\end{array}$ \\
\hline
\end{tabular}

Table 2: Optical characteristics and precision data parameters of Methods A \& B for Sitagliptin Phosphate

\begin{tabular}{|c|c|c|}
\hline Parameter & Method A & Method B \\
\hline Measured $\lambda_{\max }(\mathrm{nm})$ & 412 & 419 \\
\hline $\begin{array}{c}\text { Moloar absorptivity }\left(\text { micrograms } / \mathrm{cm}^{2} / 0.001\right. \\
\text { absorbance unit) }\end{array}$ & $25-125$ & $10-50$ \\
\hline Optimum photometric range $(\mu \mathrm{g} / \mathrm{ml})$ & $1.028 \times 10^{4}$ & $1.086 \times 10^{4}$ \\
\hline Regression equation $(\mathrm{Y}=\mathrm{mx}+\mathrm{c})$ & $30-100$ & $10-40$ \\
\hline Intercept (c) & $\begin{array}{c}\mathrm{Y}(-0.0056)=0.008 \mathrm{x} \\
+0.0070\end{array}$ & $\begin{array}{c}\mathrm{Y}(0.0046)=0.028+ \\
0.0303\end{array}$ \\
\hline Slope $(\mathrm{m})$ & -0.0056 & 0.0046 \\
\hline Standard error of estimate & 0.008 & 0.028 \\
\hline Correlation coefficient $(\mathrm{r})$ & 0.0070 & 0.0303 \\
\hline \% RSD & 1 & 0.998 \\
\hline Color stability (hours) & 0.3217 & 0.445 \\
\hline Confidence intervals (upper limit $=1)$ & 1 & 1.30 \\
\hline
\end{tabular}

\section{References}

[1]. D.Kim, Wang L and Beconi M, J.Med.Chem. 2005; 48: 141-151.

[2]. Herman G.A, Stein P.P, Thornberry N.A, and Wagner J.A, Dipeptidyl Peptidase-IV Inhibitors for the treatment of Type II Diabetes: Focus on Sitagliptin, Clin Pharmacol Ther. 2007; 81: 761-767.

[3]. Green B.D, Flatt P.R and Bailey C.J, Dipeptidyl Peptidase IV (DPP IV) Inhibitors. A newly emerging drug class for the treatment of Type II Diabetes, Diab Vasc Dis Res. 2006 B; 3: 159-165.

[4]. Baptist Gallwitz, Review of Sitagliptin Phosphate: A novel treatment for Type II Diabetes, Vasc Health Risk Manag. 2007; 3(2): 203-210.

[5]. Aschner P, Kipnes M, Lunceford J, Sanchez M, Mickel C, Williams-Herman D, Sitagliptin monotherapy improved glycemic control in patients with Type II Diabetes, Diabetologia. 2006; 49 (Supl 1): 5.

[6]. Aschner P, Kipnes MS, Lunceford JK, Sancez M, Mickel $C$, and Williams-Herman D, Effect of the dipeptidyl peptidase-4 inhibitor Sitagliptin as monotherapy on glycemic control in patients with Type II Diabetes, Diabetes Care. 2006 C; 29: $2632-2637$.

[7]. Raz I, Hanefeld M, Xu L, Caria C, Williams-Herman D and Khatami H, Sitagliptin Study 023 Group. Efficacy and safety of the dipeptidyl peptidase-4 inhibitor Sitagliptin as monotherapy in patients with Type II Diabetes mellitus, Diabetologia. 2006; 49(11): 2564-2571.

[8]. Koenig R.J, Peterson C.M, Jones R.L, Saudek C, Lehrman M and Cerami A, "Correlation of glucose regulation and hemoglobinAIc in Diabetes mellitus", N. Engl. J. Med. 1976; 295 (8): 417-420.

[9]. Prasad, Ch. Hari, Sushma, P. Chandy, Rao, G. Devala, Babu, G. Sudhakara Sai, Oriental Journal of Chemistry. 2009; 26(3): 12111213.

[10]. Bala Sekaran, C and Prameela Rani, An International Journal of Pharmacy and Pharmaceutical Sciences. 2007; 2(4):138-142.

[11]. Ravanello, Aline, Dadalt, Gabriele, Torres, Bruna G. S, Hurtado, Felipe K, Marcolino, Ana I. P, Rolim and Clarice M. B, Latin American Journal of Pharmacy. 2005; 29(6): 962-967.

[12]. Sachin Patil, B. Ramesh, A.R. Hareesh and Kiran Patil, Validated UV Spectrophotometric Method for Estimation of Sitagliptin Phosphate in Tablet Dosage Form, Research Journal of Pharmacy and Technology. 2010; 03(03): 798-802.

[13]. Tang Yao, LI Xiang et al., RP-HPLC determination of Sitagliptin phosphate, Chinese Journal of Pharmaceutical Analysis. 2009; 29(8): 1370-1372.

[14]. Sachin Patil, B Ramesh, AR Hareesh et al., Development and Validation of RP-HPLC Method for the Estimation of Sitagliptin Phosphate in Tablet Dosage Form, Asian J. Research Chem. 2010; 3(3): 653-655.

[15]. Stella Vincent H, James Reed R, Bergman A.J, Elmore C.S et al, Metabolism and excretion of dipeptidase 4 inhibitor (14C) Sitagliptin in humans, Drug Metab Dispos. 2007; 35: 533-538.

[16]. Zeng W, Musson D.G, Fisher AL, Chen L, Schwartz M.S, Woolf E.J et al, Determination of Sitagliptin in human urine and hemodialysate using turbulent flow online extraction and tandem mass spectrophotometry, J Pharmaceut Biomed. 2008; 46: 534542 . 